\title{
O Contexto da Educação Especial Brasileira: Deficiência Visual
}

\author{
AZEVEDO, Francielle Caroline [1], BUZON, Eliane [2],CHIACCHIO, Simon Skarabone Rodrigues [3]
}

AZEVEDO, Francielle Caroline; et.al. O Contexto da Educação Especial Brasileira: Deficiência Visual. Revista Científica Multidisciplinar Núcleo do Conhecimento. Edição 02. Ano 02, Vol. 01. pp 676-693, Abril de 2017. ISSN:2448-0959

\section{RESUMO}

A proposta do presente trabalho é analisar se os cursos de formação docente oferecem embasamento teórico-prático para que os professores possam trabalhar com alunos que apresentam deficiência visual. Atualmente há avanços e retrocessos na temática da inclusão de pessoas com deficiência na escola. Entre avanços e retrocessos, os professores, muitas vezes, não se sentem preparados para lidar com alunos com “Necessidades Educacionais Especiais-NEE". Na perspectiva deste estudo, de revisão bibliográfica, tem o objetivo de analisar como está sendo organizada a formação de professores, para que possam trabalhar com alunos que possuem deficiência visual. É relevante salientar que há necessidade de uma formação mais específica na graduação, tendo em vista a educação especial e necessidade de se trabalhar com a inclusão de alunos com deficiência nas classes comuns. Devido à falta de uma formação teórica e prática com qualificação adequada oferecida pelas universidades no curso de graduação em pedagogia, se faz necessário um alicerce mais abrangente aos futuros profissionais que desejam lecionar, na educação especial, principalmente aqueles que querem se dedicar a alunos com algum comprometimento visual.

Palavras-Chave: Formação de Professores, Deficiência Visual, Educação Especial.

\section{INTRODUÇÃO}

Este artigo tem como objetivo refletir sobre o contexto da educação especial brasileira. Estudos recentes apresentam a necessidade de professores, gestão escolar e sociedade aproximarem-se das necessidades educacionais das pessoas com deficiência no âmbito da educação inclusiva e completa (CHIACCHIO, 2014).

No artigo, apresentamos alguns dos termos mais atuais, como Pessoas com Deficiência (PcD) e também termos menos usuais, mas que constam em alguns documentos e bibliografias mais anigas acerca da temática, destacamos nesse contexto o termo "Necessidades Educativas Especiais" - NEE. 
A prática docente, leva em consideração em sua grande maioria que os alunos, estão aptos e apresentam as dificuldades comuns ao período escolar, e em muitos casos desconsidera particularidades, por exemplo, a baixa visão e/ou cegueira.

Por meio destes pressupostos, é possível identificar a gama de obstáculos que o professor deve superar, e que estão correlacionadas com o ensino que é recebido pelo aluno na escola, por meio da aprendizagem.

Partimos do pressuposto que a educação completa seria a capacidade da escola de educar considerando todas as especificidades, ou seja, não haveria dentro desse contexto a necessidade de se dividir a educação em diferentes vertentes educacionais.

No caso da educação inclusiva, é necessário que a escola seja um local com amplas condições e qualidade e possibilidades para o educando, podendo assim, ter um ambiente propício para o respeito à diversidade, ou seja, sem qualquer tipo de discriminação, preconceito e exclusão, situação essa ainda muito presente em diferentes contextos educacionais.

É relevante propor a aprendizagem e o desenvolvimento integral do indivíduo, biapsicosocial, que são fatores fundamentais para que a escola realize um trabalho que atenda todas as especificidades de cada aluno com ou sem algum tipo de deficiência.

O presente trabalho propõe contribuir com algumas reflexões em relação à formação geral de professores e sugerir possíveis formas de como trabalhar com pessoas que possuem algum tipo de deficiência visual.

Diante do exposto também visa refletir sobre a própria atuação docente em sala de aula verificando se há mais preparo dos atuais docentes para um trabalho com situações novas e mais complexas no que diz respeito às diferenças dentro da sala de aula.

\subsection{O CONTEXTO DA INCLUSÃO NA EDUCAÇÃO BRASILEIRA: A PARTIR DOS MARCOS LEGAIS}

A inserção e inclusão estão incluídas e correlacionadas na Constituição de (1988), na Lei de Diretrizes e Bases (1996) e no Atendimento Educacional Especializado (2007).

O atual direito à educação está contemplado na Constituição Federal de 1988, discuti os aspectos da Educação, Cultura e Desporto abrangendo os artigos legais que regem os aspectos educacionais.

O artigo 205 contempla que: "A educação, direito de todos e dever do Estado e da família, será promovida e incentivada com a colaboração da sociedade, visando ao pleno desenvolvimento da pessoa, seu preparo para o exercício da cidadania e sua qualificação para o trabalho", visto que:

Em 1990 esse direito é confirmado na Declaração Mundial sobre Educação Para Todos, independentemente de suas diferenças particulares. É reforçado pelas diversas declarações das Nações Unidas, que culminaram na Declaração de Igualdade de Oportunidades para as Pessoas com Deficiência, assinado em 1993 e publicado em 1994, garantindo que a educação de pessoas deficientes seja parte integrante do sistema educativo. (SHIMAZAKI, MORI, 2012, p.36) 
A inclusão deve ser um procedimento que motiva a todos os alunos para que façam parte do mesmo contexto escolar, compartilhando das mesmas atividades, ainda que adaptadas para atender as diferenças individuais.

Segundo o artigo 206, no parágrafo I, esse estabelece que deve existir "igualdade de condições para o acesso e permanência na escola” (BRASIL. Constituição Federal, 1998).

Visando o direito à inclusão na escola de ensino regular, que ganhou força a partir de 1994 com a divulgação da Declaração de Salamanca, tendo sua origem na Conferência Mundial sobre a Educação para Todos estes documentos trouxeram alguns princípios, políticas e práticas coerentes às necessidades especiais.

Conforme Zuttin (2008) apud Cretella (1991), o Direito a Educação é um dos primeiros Direitos Sociais, que é solicitada pela família. Cabe ao Estado o dever de oferecer a todo cidadão, a matrícula nas instituições de ensino público, se houver a insuficiência no número vagas, devido à grande demanda de atendimento aos alunos, estes tem que ser inseridos em um colégio particular, que será custeado pelo Estado, visto que isto foi definido por uma regra jurídica constitucional.

Já em relação ao artigo 208, em no parágrafo III, menciona que o "atendimento educacional especializado aos portadores de deficiência será feito preferencialmente na rede regular de ensino” (BRASIL, 1988).

Em outras palavras, os alunos com deficiência que frequentam escolas de ensino regular têm o direito à educação, com o atendimento especializado de acordo com as suas necessidades individuais que se exige no âmbito educacional, para que estes alunos possam acompanhar o desempenho dos outros discentes, que o circunda em sala de aula.

O acesso, permanência e continuidade dos estudos desses alunos deve ser garantido nas escolas comuns para que se beneficiem desse ambiente escolar e aprendam conforme suas possibilidades (FÀVERO, PANTOJA, MANTOAN, 2007, p.28).

A Lei de Diretrizes e Bases da Educação Nacional tem o objetivo de fazer com que:

A tramitação da LDB foi, nesse contexto, expressão dos embates travados no âmbito do Estado e nos desdobramentos por ele assumidos no reordenamento das relações sociais e das mudanças tecnológicas sob a ideologia da globalização da economia. Assim, a referência básica para a educação nacional, o texto da LDB incorporou, ao longo de sua tramitação, vários dispositivos referentes à educação, objeto de projetos de lei e de decretos, de reforma constitucional (ZUNTTIN, 2008, p.56)

Em especial o artigo $4^{\circ}$, inciso III, corrobora com a Constituição Federal, quando menciona que o Atendimento Educacional Especializado deve ser gratuito aos educandos com necessidades especiais e oferecido, preferencialmente, na rede regular de ensino.

Art. 58 $8^{\circ}$ Entende-se por educação especial, para os efeitos desta Lei, a modalidade de educação escolar, oferecida preferencialmente na rede regular de ensino, para educandos portadores de necessidades especiais. 
- $1^{\circ}$. Haverá, quando necessário, serviços de apoio especializado, na escola regular, para atender às peculiaridades da clientela de educação especial.

- $2^{\circ}$. O atendimento educacional será feito em classes, escolas ou serviços especializados, sempre que, em função das condições específicas dos alunos, não for possível a sua integração nas classes comuns de ensino regular.

- $3^{\circ}$. A oferta de educação especial, dever constitucional do Estado, tem início na faixa etária de zero a seis anos, durante a educação infantil.

Art. $59^{\circ}$. Os sistemas de ensino assegurarão aos educandos com necessidades especiais:

I - currículos, métodos, técnicas, recursos educativos e organização específica, para atender às suas necessidades;

II - terminal idade específica para aqueles que não puderem atingir o nível exigido para a conclusão do ensino fundamental, em virtude de suas deficiências, e aceleração para concluir em menor tempo o programa escolar para os superdotados;

III - professores com especialização adequada em nível médio ou superior, para atendimento especializado, bem como professores do ensino regular capacitados para a integração desses educandos nas classes comuns;

IV - educação especial para o trabalho, visando a sua efetiva integração na vida em sociedade, inclusive condições adequadas para os que não revelarem capacidade de inserção no trabalho competitivo, mediante articulação com os órgãos oficiais afins, bem como para aqueles que apresentam uma habilidade superior nas áreas artística, intelectual ou psicomotora;

V - acesso igualitário aos benefícios dos programas sociais suplementares disponíveis para o respectivo nível do ensino regular.

Art. $60^{\circ}$. Os órgãos normativos dos sistemas de ensino estabelecerão critérios de caracterização das instituições privadas sem fins lucrativos, especializadas e com atuação exclusiva em educação especial, para fins de apoio técnico e financeiro pelo Poder Público.

Parágrafo único: O Poder Público adotará, como alternativa preferencial, a ampliação do atendimento aos educandos com necessidades especiais na própria rede pública regular de ensino, independentemente do apoio às instituições previstas neste artigo. (BRASIL, Lei nº 9.394/96).

Toda e qualquer lei carece ser decodificada e ponderada trazendo como base os princípios fundamentais que definem a Constituição Federal.

\section{ESCLARECENDO DEFICIÊNCIA VISUAL}

O primeiro contato que o ser humano estabelece com o mundo começa a ser constituído após o nascimento. Isso ocorre por meio da utilização de todos os nossos sentidos (visão, audição, tato, olfato e paladar), pois cada um deles pode nos proporcionar diferentes formas de aprendizagem, porque cada um dos sentidos tem uma função determinada no corpo humano, possibilitando assim um desenvolvimento 
humano em todas as esferas.

É a visão que nos possibilita compreender/entender o mundo que vivemos, pois é com este sentido que podemos dar um significado para os objetos, conceitos e ideias de tudo que enxergamos ou visualizamos; isso ocorre porque, na maioria das vezes estabelecemos a comunicação por meio de imagens, ou seja, através da chamada comunicação visual (GORGATTI e COSTA).

No entanto, para uma pessoa que tem deficiência visual, a comunicação visual é mais difícil de realizar, pois este tipo de componente na maioria das vezes fica prejudicado e, melhorar a capacidade de comunicação visual só é possível com a ajuda de imagens, desenhos, figuras, signos, gráficos, vídeos entre outros, se forem adaptados (GORGATTI e COSTA). Somente assim estes elementos podem se tornar uma forma de comunicação para que as pessoas com deficiência visual tenham a oportunidade de expressar uma ou mais ideias e também para que tenham a oportunidade de entender o mundo em que estas pessoas estão inseridas.

Para que possamos compreender os conceitos sobre a deficiência visual, será necessário que se entenda as definições que são dadas a estas pessoas, as quais tenham algum tipo de perda visual, seja ela de forma total ou parcial; para que possa haver um entendimento mais conciso, são estipulados parâmetros de classificação na deficiência visual, para que se percebam as diferenças e características no momento de se dar subsídios básicos nas práticas pedagógicas aos alunos que têm algum grau de comprometimento visual.

A deficiência visual é característica pela perda parcial ou total da capacidade visual, em ambos os olhos, levando o individuo a uma limitação em seu desempenho individual (GORGATTI e COSTA, 2005, p.29)

Para que os profissionais da saúde e da educação possam diferenciar os graus de deficiência visual, foram catalogados os diferentes tipos de doenças, que comprometem a acuidade visual. No entanto, tendo em vista tudo o que se pode considerar em termos oftalmológicos, foi necessário criar uma classificação para se estabelecer o grau de deficiência da pessoa.

Para as autoras (LIMA; NASSIL e FELIPPE, 2007) a definição de deficiência visual se dá em dois momentos, um no ponto de vista legal e o outro no educacional.

No ponto de vista legal as classificações são apresentadas, devido aao fato de serem utilizadas em diagnósticos para se informar qual é o percentual que o indivíduo abrange de deficiência visual, para os especialistas da área oftalmológica. A cegueira: “...a acuidade visual é igual ou menor que 0,05 no melhor olho com a melhor correção óptica” (LIMA, NASSIF e FELIPPE, 2007, p.5).

A baixa visão é determinada, a partir da quantidade de espectro do melhor olho não incide de $30 \% \mathrm{em}$ relação ao que se avalia visão normal, ainda com tratamento clínico pautado ou uso de óculos. Toda pessoa com baixa visão distingue de forma diferenciada, de acordo com as corruções que podem acontecer na função visual (em detrimento da acuidade visual, na visão de cores, no campo visual, na sensibilidade ao contraste, na adequação à luz). De acordo com Lima, Nassif e Felippe, o quadro de:

BAIXA VISÃO: a acuidade visual entre 0,3 e 0,05 no melhor olho, com a melhor correção óptica; os quais a somatória da mediada do campo visual em ambos os olhos for igual ou menor que $60^{\circ}$ ou a 
ocorrência simultânea de quaisquer das condições anteriores. (LIMA, NASSIF e FELIPPE, 2007, p.5).

Este tipo de classificação/definição caracteriza a pessoa com deficiencia visual em: perda parcial ou total de sua capacidade visual, que são conhecidas também pelos termos "cegueira e baixa visão ou visão subnormal”, na área educacional. A cegueira: “...perda total ou resíduo de visão leve a pessoa a necessitar do sistema Braille como meio de leitura e escrita. (LIMA, NASSIF e FELIPPE, 2007, p.5).

Para se detectar a deficiência visual é necessário que se realize exames para saber qual é a quantidade de acuidade que a pessoa tem, pois isso pode interferir na dimensão e na distância que a pessoa consegue visualizar. De acordo com o autor caracterizando a baixa visão ou visão subnormal:

BAIXA VISÃO ou VISÃO SUBNORMAL: comprometimento do funcionamento de ambos os olhos, mesmo após o tratamento ou correção. As pessoas com baixa visão possuem resíduos visuais em graus que lhes permite ler todas as impressões ampliadas ou com uso de recursos opticos específicos. (LIMA, NASSIF e FELIPPE, 2007, p.5).

A separação por áreas de deficiência refletia a diversidade de aspirações existentes com que o Movimento do Conselho Brasileiro de Pessoas Portadoras de Deficiência de 1984, e as especificidades de cada grupo, as dificuldades de consenso, sobretudo quanto ao exercício da liderança, fizeram com que o movimento decidisse tomar outro rumo. Essa decisão, no entanto, não significou uma cisão em vários movimentos, mas uma alteração decorrente da decisão amadurecida nas discussões entre as pessoas com deficiência, reflexo dos conflitos internos ao próprio movimento.

A estratégia de separar por área de deficiência visava melhor atender às especificidades de cada uma, sem excluir a ação conjunta para as questões de âmbito geral. Prova disso foi à articulação nacional empreendida pelas pessoas com deficiência em 1987 e 1988, por ocasião das discussões da nova Constituição Federal (JÚNIOR, L.; MARTINS, M. C., 2010, p. 56).

\section{A INCLUSÃO E A FORMAÇÃO DE PROFESSORES}

Alguns educadores declaravam, aos gestores escolares e aos familiares, que a criança não tinha vontade de aprender os conteúdos e atividades que eram propostas no decorrer das aulas. "As escolas que reconhecem e valorizam as diferenças têm projetos de inclusivos de educação" (MANTOAN, 2006, p.44).

A educação não prevê o uso de práticas de ensino escolar específicas para esta ou aquela deficiência e/ou dificuldade de aprender. Os alunos aprendem nos seus limites, e se o ensino for, de fato, de boa qualidade, o professor levarão em conta esses limites e explicará convenientemente as possibilidades de cada um. Não se trata de uma aceitação passiva do desempenho escolar, sim de agirmos com realismo e coerência e admitirmos que as escolas existam para formar as novas gerações, e não apenas alguns de seus futuros membros, os mais capacitados e privilegiados (MANTOAN, 2006, p.47).

Embora a inclusão escolar vem sendo disseminada em todas as partes da sociedade, os meios escolares ainda têm dificuldade em lidar com esse público. Muitas escolas agregam pessoas com deficiência, mas grande parte dos professores rotula este público como sendo carentes, não comportados, hiperativos, agressivos e tantos outros mais. 
Atividades diversificadas - pesquisas, debates e dinâmicas - avaliações que acompanhem a evolução dos alunos, a mudança da seriação para a adoção de ciclos de formação, a construção compartilhada de valores, atitudes e conceitos em sala, a mudança do caráter normalmente burocrático e fiscalizador dos demais membros da comunidade escolar e a formação de assembleias e conselhos envolvendo alunos e familiares são algumas das sugestões para a mudança das praticas tradicionais do sistema escolar (CARNEIRO, ABAURRE, SERRÃO, 2005, p.165).

A falta de infraestrutura básica dentro das sedes escolares e a despreparação dos professores polivalentes fazem com que a Lei de Diretrizes e Bases (LDB), que dá acesso e permanência à criança na escola não tenha tanta validade assim. Isso se deve porque não há o mínimo necessário para que haja acolhimento digno das pessoas que necessitam de um atendimento educacional especializado, ou como hoje ratificamos, o atendimento às especificidades do sujeito (LIMA; NASSIL e FELIPPE, 2007).

Alguns anos atrás nada se discutia sobre a inserção e inclusão de pessoas com deficiência $(\mathrm{PcD})$ dentro da escola, não só devido à falta de conhecimento dos profissionais da educação, mas também pela ausência de políticas públicas. Além disso, eram escassos os métodos aplicados nas instituições de ensino básico, os quais em nada oportunizavam ferramentas às práticas docentes.

A história da educação especial começou a ser traçada no século XVI, com médicos e pedagogos que, desafiando os conceitos vigentes na época, acreditarem nas possibilidades de indivíduos até então considerados ineducáveis. Centrados no aspecto pedagógico, numa sociedade em que a educação formal era direito de poucos, esses percursores desenvolveram seus trabalhos em bases tutoriais, sendo eles próprios os professores de seus pupilos (MENDES; 2006; p. 387).

No entanto, o que se percebe historicamente é que não existia uma preocupação de uma educação mais inclusiva, seja para pessoas com ou sem deficiência.

Por tudo isso, a inclusão implica uma mudança de perspectiva educacional, porque não atinge apenas os alunos com deficiência e os que apresentam dificuldades de aprender, mas todos os demais para que tenham sucesso na corrente educativa geral. Os alunos com deficiencia constituem uma grande preocupação para os educadores inclusivos. Porém, todos nós sabemos que a maioria dos que fracassam na escola são alunos que não vêm do ensino especial, mas que possivelmente acabaram nele (MANTOAN, 2006, p.19).

Em virtude disso, muitos docentes dizem que não sabem lidar com as diferenças que se tem em sala de aula, principalmente no atendimento de pessoas com deficiência, devido as diferentes formas de integração. Mesmo com as políticas educacionais, ainda existe o preconceito, a discriminação, a exclusão.

O preconceito é um fato histórico, principalmente contra as pessoas com deficiência, que vem sendo perpetuando durante décadas, devido a pouca informação que se tem disponível com relação ao tema.

Muitas vezes a coletividade traz consigo um olhar muito primitivo em relação aos valores que serão transmitidos para as pessoas com deficiência. Com isso o professor tem que desempenhar vários papéis, como o de ser um mediador do conhecimento científico e de mundo (MANTOAN, 2006). Consequentemente não pode se esquivar de problematizar a infraestrutura da escola principalmente a capacidade do indivíduo, já que o meio pode interferir no seu desempenho escolar, gerando assim uma 
autoestima baixa e até mesmo o desinteresse da criança nos estudos.

Assim sendo, a inserção deste público, fez com que a inclusão escolar sofresse obstáculos por falta de preparação e adaptação dentro das escolas regulares, devido às diversas problemáticas como: materiais inadequados, professores despreparados, estruturas irregulares, e outros (SILVA, 2009).

Dessa forma, a exclusão escolar se manifesta das mais diversas maneiras e o que está em jogo é a falta de conhecimento o discente diante dos padrões de cientificidade do saber (MANTOAN, 2006). Ocorre que a escola se democratizou abrindo-se a novos grupos sociais, mas não aos novos conhecimentos.

Por isso exclui os que ignoram o conhecimento que ela valoriza e não cria a possibilidade de diálogo entre diferentes instâncias epistemológicas, bem como não se abre a novos conhecimentos. $\mathrm{O}$ conhecimento evolui por recomposição, contextualização e integração de saberes e redes de entendimento e também não reduz o complexo ao simples, para aumentar a capacidade de reconhecer o caráter multidimensional de problemas e de soluções (MANTOAN, 2006).

Os sistemas escolares praticam a exclusão escolar porque são organizadas a partir de um pensamento que recorta a realidade, que permite dividir os discentes em normais e deficientes, as modalidades de ensino em regular e especial. Os professores do ensino regular consideram-se despreparados para lidar com as diferenças em sala de aula, especialmente para atender os alunos com deficiência, pois os pais de alunos sem deficiências não admitem a inclusão, por acharem que as escolas irão piorar ainda mais na qualidade de ensino se tiverem que receber alunos com deficiência.

Preconceitos distorcem o sentido da inclusão escolar, reduzindo-a unicamente à inserção de alunos com deficiência no ensino regular. Essas são as grandes barreiras a serem enfrentadas pelos que defendem a inclusão escolar, uma vez que inibem inovações para a educação de alunos em geral (MANTOAN, 2006).

Tal descriminação é gerada devido às ações que causam a segregação de pessoas, por causa da criação de salas de recurso a uma determinada parcela de alunos que necessitam de um acompanhamento mais exclusivo por parte das instituições de ensino básico sejam eles de caráter privado ou público (MANTOAN, 2006).

Bray, Leonardo e Rossato (2009), realçam que as escolas públicas e privadas não enfrentaram mudanças nos aspectos "estratégicos, metodológicos e na preparação/capacitação de profissionais", e também no que diz respeito à inclusão escolar. Eles chegaram a essa conclusão com base nas respostas da pesquisa de campo, na implantação da inclusão de alunos com deficiência em escolas comuns.

Uma consequência da carência de um planejamento mais eficaz, a implementação do projeto de abrangência escolar, acarretou problemas deficitários com relação à aprendizagem e o desenvolvimento de alunos que apresentam algum tipo de deficiência.

Bray, Leonardo e Rossato (2009), apontam que os problemas da formação de profissionais de pedagogia são devido ao pouco preparo psicológico, que se tem quando se trabalha com qualquer tipo de público. Porém, isso acontece com mais frequência quando se trabalha com os alunos com algum tipo de deficiência, pois, na maioria das vezes, o diferente não é percebido como sendo uma pessoa normal, ou seja, são considerados fora do padrão de normalidade, por causa de serem pessoas com necessidades 
educacionais especiais.

Essas ideias são pensamentos muito tradicionais para os dias de hoje, pois com todas as discussões sobre o tema da inclusão de pessoas com deficiência nas escolas de ensino regular já deveria existir um outro perfil de inclusão e aceitação. Há por parte dos educadores e de todos que manifestam o pensamento de que existe uma homogeneidade dentro de sala de aula, parece inexistir a consciência de que temos "novos saberes, novos alunos, outras maneiras de resolver problemas e de avaliar a aprendizagem" (MANTOAN, 2006, p.34).

Cada ser humano é definido por ter uma identidade única independente de sua raça, cor, crédulo, religião, sexualidade, comunidade e entre outros tantos seguimentos que foram inclusos na sociedade.

Essas formas inovadoras de diferença - de corpo, de aprendizagem, de língua, de sexualidade, de movimento, etc. - devem ser vistas não como um atributo e/ou prioridade e/ou característica "dos diferentes", mas com a possibilidade de entender a nossa compreensão acerca da intensidade e imensidade das diferenças humanas (RODRIGUES, 2006, p.27).

Conforme afirma, Rodrigues (2006) os professores precisam apropriar-se dessa concepção, perante o meio educacional, fazendo com que os profissionais não acabem se tornando pessoas com visões fictícias e ultrapassadas daquilo que é realmente importante dentro da escola.

Por isso, o plano de estudos para o melhoramento da formação docente, tem que ser mais consistente, possibilitando a realização de diferentes formas de trabalhos pedagógicos dentro do ambiente escolar, principalmente as questões que se referem à inserção de pessoas com deficiência dentro da sala de aula (MANTOAN, 2006). Dessa forma, o professor pode proporcionar vários tipos de estratégias, fazendo com o aluno com deficiência e outros alunos se desenvolvam e melhorem o desempenho escolar.

Muitas vezes as questões educacionais, são deixadas de lado pelos poderes governamentais, principalmente no que diz respeito à inserção de pessoas com deficiência dentro do contexto escolar, geralmente estes alunos necessitam de atendimento especializado.

Porém, nem sempre os colégios públicos e privados oferecem um atendido adequado, devido grande parte dos profissionais que realizam este atendimento não são gabaritadas para trabalhar com os alunos de educação especial. E, as instituições de ensino não recebem nenhum tipo de apoio do poder público, mesmo com várias leis que redigem os assuntos de educação especial.

Consideramos, pois, a política de inclusão que garante acesso e permanência a todo aluno com necessidades educativas especiais no ensino comum, na formação do professor, seria importante prever, inicialmente, um preparo de efetiva qualidade para lidar com a diversidade, além de (in) formação específica em educação especial, no curso de formação inicial (magistério) e na graduação (pedagogia) para prover os apoios pedagógicos previstos nas legislações (RODRIGUES, 2006, p.39).

A Declaração de Salamanca (1994) é um importante documento que desencadeia a normatização e elaboração das leis de inclusão que há atualmente. Ela é de estrema importância, pois pode ampliar e incorporar discussões, bem como aumentar a possibilidade de aprofundar a vinculação de diversos temas. E, dessa maneira, contribui para que as transformações nas intuições de educação básica sejam colocadas 
em prática pelo poder público.

Todavia, devido à falta de investimentos, a criação do sistema nacional de formação de professores, faz com que as propostas não tenham um planejamento eficaz para que a educação inclusiva seja implementada de fato em todas as redes de ensino existentes em nosso país.

É nesse contexto que se organiza a educação, e nela a educação especial, já que, no projeto neoliberal, os objetivos do plano educacional estão vinculados à formação de uma força de trabalho com um nível mais alto de conhecimento, apto e flexível para acompanhar as exigências das novas tecnologias (CAIADO, 2006, p.16).

Caiado (2006) pontua em sua obra literária que no preâmbulo da Declaração de Salamanca, expõe de forma bem clara que a Conferência teve como objetivo declarar e consolidar o compromisso colocado neste encontro mundial, de que a "educação é um direito de todos".

\section{CONSIDERAÇÕES FINAIS}

O tema é muito relevante e necessário para ser discutido na educação brasileira. A exclusão acontece não somente pelo preconceito, mas também pela falta de prática do profissional em não saber lidar com o deficiente visual, e tal prática precisa começar a ser repensada nas graduações, assim como também em nossa sociedade como um todo.

Embora a inclusão escolar venha sendo disseminada em todas as partes da sociedade, os meios escolares ainda têm dificuldade em lidar com esse público. Muitas escolas agregam pessoas com deficiência, mas grande parte dos professores rotula este público como sendo carente, não comportado, hiperativo, agressivo e tantos outros rótulos.

De acordo com Chiacchio (2014), a falta de infraestrutura básica dentro das sedes escolares e a despreparação dos professores polivalentes fazem com que a lei que dá acesso e permanência à criança na escola não tenha tanta validade assim. Isso se deve porque não há o mínimo necessário para que haja acolhimento digno das pessoas que necessitam de um atendimento educacional especializado.

Alguns anos atrás nada se debatia em cima da inserção e inclusão de pessoas com deficiência, dentro da instituição de ensino, é imparcial à ausencia de compreensão por parte dos profissionais que trabalham na área da educação, contudo há uma carência nas políticas públicas (CHIACCHIO, 2014). Além do mais, aconteciam esporadicas metodologias sobrepostos nos estabelecimentos de ensino básico, os quais não se ofereciam instrumentos teóricos e práticos para os docentes.

Em decorrência disso, inumeros educadores afirmam que jamais trabalharam com as discriminações que há em sala de aula, especialmente o auxílio para discentes com deficiência, necessário as diversas maneiras de integração. Mesmo existindo as políticas educacionais, ainda há o preconceito, a discriminação, a exclusão.

O preconceito é um fato histórico, principalmente contra as pessoas com deficiência, que vem sendo perpetuando durante décadas, devido a pouca informação que se tem disponível com relação ao tema. 
Por isso, o plano de estudos para o melhoramento da formação docente, tem que ser mais consistente, possibilitando a realização de diferentes formas de trabalhos pedagógicos dentro do ambiente escolar, principalmente nas questões que se referem à inserção de pessoas com deficiência dentro da sala de aula (CHIACCHIO, 2014). Dessa forma, o professor pode proporcionar vários tipos de estratégias, fazendo com o aluno com NEE e outros alunos se desenvolvam e melhorem o desempenho escolar.

Todavia, devido à falta de investimentos, a criação do sistema nacional de formação de professores, faz com que as propostas não tenham um planejamento eficaz para que a educação inclusiva seja implementada de fato em todas as redes de ensino existentes em nosso país.

\section{REFERÊNCIAS}

BRASIL. Constituição Federal. Promulgada em 05 de outubro de 1988.

BRASIL. Ministério da Educação e do Desporto. Lei de Diretrizes e Bases da Educação Nacional. Lei no 9.394/96, Brasília.

BRIDI, F. R. S.; VILLAGRAN, V. M. Educação inclusiva e formação de professores. Inclusão: Revista de Educação Especial. V.6, nº 1, p.62 - 63, janeiro - junho, 2006.

CAIADO, K.R.M. Aluno Deficiente Visual na Escola: Lembranças e Depoimentos. Campinas, SP: Autores Associados, 2006.

CARNEIRO, R.; ABAURRE, N.W.; SERRÃO, M. A. Transversalidade e Inclusão: Desafios para o educador. Rio de Janeiro, RJ: SENAC Nacional, 2005.

CHIACCHIO, Simon Skarabone Rodrigues. Saberes docentes fundamentais para a promoção da aprendizagem do aluno surdo no ensino superior brasileiro. 2014. $217 \mathrm{f}$. Tese (Doutorado em Educação: Currículo) - Pontifícia Universidade Católica de São Paulo, 2014. Instituição Financiadora: CAPES.

FÁVERO, Eugênia Augusta Gonzaga; PANTOJA, L. M. P.; MANTOAN, M. T. E. . Atendimento Educacional Especial: aspectos legais. In: Eugênia A. Fávero; Luísa de M.P. Pantoja; Maria T.E. Mantoan. (Org.). Atendimento Educacional Especializado: Aspectos legais e orientações pedagógicas. São Paulo: MEC/SEESP, 2007, v. 2, p. 25-42.

GORGATTI, M.G.; COSTA, R. F. Atividade física adaptada. Barueri, SP: Manole, 2005.

JÚNIOR, L.; MARTINS, M. C. (Comp.). História do Movimento Político das Pessoas com Deficiência no Brasil. - Brasília: Secretaria de Direitos Humanos. Secretaria Nacional de Promoção dos Direitos da Pessoa com Deficiência, 2010. 443p.

LEONARDO, N.S.; BRAY, C.T.; ROSSATO, S.P.M. Inclusão Escolar: um estudo acerca da implantação da proposta em escolas de ensino básico. Revista Brasileira de Educação Especial. V.15, $\mathrm{n}^{\circ}$ 2, p. 289 - 306, maio - agosto, 2009. 
LIMA, E, C.; NASSIF, M. C. M.; FELLIOE, M. C. G.C.; Convivendo com a Baixa Visão: da Visão à Pessoa Idosa. São Paulo: Fundação Dourina Nowill para Cegos, 2007.

MANTOAN, M.T.E. Inclusão Escolar: O que é? Por quê? Como fazer? São Paulo. Moderno, 2006. 64p.

MENDES, E. G. A radicalização do debate sobre inclusão escolar no Brasil. Revista Brasileira de Educação. V.11, n 33, p.387-405, setembro - dezembro, 2006.

RODRIGUES, D. (org) Inclusão e Educação: Doze olhares sobre a educação inclusiva. São Paulo, SP: Summus, 2006.

SASSAKI, Romeu Kazumi. Terminologia sobre deficiência na era da inclusão. Revista Nacional $d$ Reabilitação, São Paulo, ano 5, n. 24, jan/fev. 2002, p. 6-9.

SHIMAZAKI, E. M.; MORI, N. N. R. Fundamentos da educação especial. In: Nerli Nonato Ribeiro Mori; Crsitina Cerezuela. (Org.). Fundamentos da educação especial. 1ed. Maringá: EDUEM, 2012, v. 1, p. 31-41.

SILVA, E. Formação de professores em educação especial: a experiência da Unesp- Campus de Marilia- SP, 2009.

Zuttin, M. A. S. Entre o dito e o feito: a garantia de permanência dos alunos no ensino fundamental nas escolas estaduais do município de Araras-SP -- São Carlos: UFSCar, 2008.

[1] Graduada do Curso de Licenciatura em Pedagogia da FHO - Fundação Hermínio Ometto - Uniararas.

[2] Professora Especialista do Curso de Licenciatura em Pedagogia da FHO - Fundação Hermínio Ometto.

[3] Professor Dr. no Instituto de Logística da Aeronáutica, Laureate International Universities e Estácio de Sá, Pesquisador no Programa de Educação: Currículo na Pontifícia Universidade Católidca de São Paulo PUC-SP.

\section{PUBLIQUE SEU ARTIGO CIENTÍFICO EM:}

https://www.nucleodoconhecimento.com.br/enviar-artigo-cientifico-para-submissao 